\title{
Possibilidades para a inserção da educação ambiental na formação docente
}

\author{
Possibilities for the integration of environmental education in teacher training
}

Carlos Alberto Vasconcelos*

\section{Resumo}

Discutir formação de professores envolve, dentre outras questões, a socioambiental. A temática ambiental no processo educativo oferece expressividade na sociedade e desafios da formação de professores para o século $\mathrm{XXI}$, desencadeando posturas e atuações mediante as dificuldades socioambientais tanto em nível temático quanto metodológico. Com essa acepção, este artigo trata e aponta propostas alternativas para inserção da educação ambiental nos cursos de formação de professores. É um trabalho de cunho bibliográfico, baseado em documentos oficiais, pesquisas desenvolvidas, além de observação e experiências. De antemão, pode-se induzir que a inserção da educação ambiental é mais adequada se desenvolvida de forma interdisciplinar também no ensino superior; há divergências no entendimento parcial da Política Nacional de Educação Ambiental quanto à operacionalização da educação; traçar políticas que contemplem a participação de professores em cursos voltados para a temática, elaboração e implementação de projetos e programas em educação ambiental. Exigem-se processos específicos de formação inicial, que devem ser implantados nos cursos de licenciatura, especificamente no currículo.

Palavras-chave: Educação ambiental. Formação de professores. Inserção curricular.

\section{Abstract}

Discuss teacher training involves, among other issues, the environmental social. The environmental theme in the educational process provides expressiveness in society and challenges of training teachers for the twenty-first century, unchaining postures and actions by social and environmental problems both in thematic and methodological. With this understanding, this essay handle and points out alternative proposals for inclusion of environmental education in teacher training courses. It is a work of bibliographic nature, based on official documents, researches developed, beyond observation and experience. Beforehand, can lead to the inclusion of environmental education is more appropriate if developed in an interdisciplinary manner also in Higher Education; there are differences in partial understanding of the National Environmental Education, as the operationalization of Education; designing policies that possibility the participation of teachers in courses focusing on the theme, design and implementation of projects and programs in environmental education. Demand specific processes of initial training should be implemented in undergraduate programs, specifically in the curriculum.

Keywords: Environmental education. Training of teachers. Curricular integration.

Recebido em: 04/12/2016 - Aprovado em: 17/06/2017

http://dx.doi.org/10.5335/rep.v24i2.7418

Pós-doutor em Educação Contemporânea na Universidade Federal de Pernambuco. Docente do Departamento de Educação e do Núcleo de Pós-Graduação em Ensino de Ciências e Matemática da Universidade Federal de Sergipe (UFS). E-mail: geopedagogia@yahoo.com.br 


\section{Introduzindo a questão}

A relação homem-natureza e a dos grupos sociais entre si, bem como a forma de apropriação dos recursos naturais, são fatores determinantes do estado atual do meio ambiente e da qualidade de vida da sociedade. A educação ambiental (EA) tem diante de si um desafio permanente em oportunizar o aprimoramento dessas inter-relações. A sociedade se apropria da natureza, e este processo traz reflexo social, cultural, histórico e econômico. É nesse contexto que buscamos discorrer sobre a EA, sua evolução, seus desafios, sua importância e suas dimensões (LEÃO, 2002).

Há um bom tempo, as questões ambientais se apresentam como um dos problemas urgentes a serem resolvidos, a fim de que a vida do homem na Terra seja preservada e que suas interferências, muitas vezes impensadas, sobre a natureza sejam revistas. Após a Revolução Industrial, no século XVIII, os recursos naturais têm sido utilizados de forma desordenada, e a natureza vem sendo degradada de forma acelerada pelo ser humano.

De antemão, podemos dizer que a EA é todo processo cultural que objetiva a formação de indivíduos capacitados a coexistir em equilíbrio com o meio. Processos informais, não formais e formais já estão conscientizando muitas pessoas e intervindo positivamente, se não solucionando, despertando para o problema da degradação crescente do meio ambiente, buscando novos elementos para uma alfabetização (BRANCO, 1998).

Segundo Alphandery (1992), a EA envolve uma discussão temática de reapropriação de certos valores que, muitas vezes, não estão no nível imediato da consciência e se encontram reprimidos ou "recalcados" através de um longo processo histórico. Ele entende que os antecedentes históricos da EA estão no crescimento demográfico exponencial humano e, consequentemente, na depleção dos recursos naturais, na reprodução de tecnologias poluentes e de baixa eficiência energética bem como nos sistemas de valores que propiciam a expansão ilimitada do consumo.

Reconhecer os problemas e estudar suas causas e consequências e o tipo de sociedade que os originou levam à interrogação de suas causas e do papel da escola diante dos fatos e do modo de agir perante esses problemas.

Com essa abordagem, os Parâmetros Curriculares Nacionais (PCNs) destacam que a função principal da EA:

É contribuir para a formação de cidadãos conscientes, aptos para decidirem e atuarem na realidade sócio-ambiental [sic] de um modo comprometido com a vida, com o bem-estar de cada um e da sociedade local e global. Para isso é necessário que, mais do que informações e conceitos, a escola se proponha a trabalhar com atitudes, com formação de valores, com o ensino e a aprendizagem de habilidades e procedimentos. E esse é um grande desafio para a educação (BRASIL, v. IX, 1998a, p. 29). 
Semelhante a essa concepção, a principal função do trabalho com o tema transversal Meio Ambiente é contribuir para a formação de cidadãos conscientes, aptos a decidir e atuar na realidade socioambiental, de um modo comprometido com a vida, com o bem-estar de cada um e da sociedade, local e global. Para isso, é necessário que, mais do que informações e conceitos, a escola se proponha a trabalhar com atitudes, com formação de valores, com o ensino e a aprendizagem de procedimentos. E este é um grande desafio para a educação como um todo: ter um sentido, que, para Charlot, "é produzido por estabelecimento de relação, dentro de um sistema, ou nas relações com o mundo ou com os outros” (2005, p. 56).

Com essa visão, para a inserção da EA no currículo de formação de professores, é mister trabalhar com professores que formam professores, ou seja, nas licenciaturas. Perante tal premissa, levamos em consideração a nossa experiência nesses cursos, partindo das experiências sobre a temática, teorizando e apontando estilos que conduzam à conscientização, à reflexão, à implementação de ações que contribuam para a formação integral e humana do professor, tendo em vista que as questões ambientais ainda são frequentemente focalizadas na perspectiva das ciências naturais. No entanto, sua ocorrência relaciona-se diretamente com a natureza sociopolítico-cultural, explicada pelas ciências do comportamento (humanas e sociais), ressaltando que a superação dos problemas ambientais, a partir dessa ótica, depende da formação de comportamentos lúcidos, críticos e criativos, ou seja, consciência ambiental e exercício da cidadania.

Para o desempenho desses comportamentos, a escola, entre outras instituições que tratam das questões ambientais, tem uma importante contribuição, inclusive para inserir no currículo atividades que favoreçam a atuação de agentes transformadores para colocar conhecimentos das ciências sociais a serviço da formação de docentes, para lidar com a questão natural/ambiental. Salientam-se, atualmente, as diversas opções a partir dos programas governamentais de cursos de educação continuada para professores via Universidade Aberta do Brasil (UAB), tentando suprir esta carência, ofertando cursos para aprimoramento de professores, em especial, da educação básica, visto que estes são os agentes transformadores que irão conviver diretamente com a realidade dos alunos; ou seja, esses profissionais serão os atores que fomentarão um trabalho de conscientização dos alunos sobre a importância do cuidado e da manutenção dos recursos naturais, inserindo aí a própria humanidade.

Atualmente, a Secretaria de Educação Continuada, Alfabetização, Diversidade e Inclusão (Secadi), em articulação com os sistemas de ensino, implementa políticas educacionais nas áreas de alfabetização e educação de jovens e adultos, educação ambiental, educação em direitos humanos, educação especial, do campo, 
escolar indígena, quilombola e educação para as relações étnico-raciais. O objetivo da Secadi é contribuir para o desenvolvimento inclusivo dos sistemas de ensino, voltado à valorização das diferenças e da diversidade, à promoção da educação inclusiva, dos direitos humanos e da sustentabilidade socioambiental, visando à efetivação de políticas públicas transversais e intersetoriais. Tal secretaria tem dado grande passo em relação à reversão da situação, até então, posta sobre a prática e os conhecimentos pertinentes à educação ambiental (BRASIL, 2012).

Devido ao seu caráter interdisciplinar, não existe uma técnica específica para tratar a educação ambiental. Deve-se, porém, estar atento à coerência de conteúdo dos materiais didáticos, às dinâmicas de discussão e apreciação das opiniões, à simulação de situações envolvendo questões ambientais, à promoção de trabalhos de campo, dentre outras atividades.

Ressalta-se que a formação de educadores ambientais para atuar com e na realidade atual requer, principalmente das universidades e, em especial, de seus projetos políticos pedagógicos, a necessidade de redimensionamento e integração entre as disciplinas. Tal formação requer, também, a convivência cotidiana com um currículo que ainda é constituído por compartimentos estanques e incomunicáveis, que produzem uma formação humana e profissional insuficiente para alunos e professores no enfrentamento das práticas sociais que exigem formação crítica e competente (TOZONI-REIS, 2004).

A partir dessas colocações iniciais, questiona-se: por que os professores da educação básica ainda não estão preparados para lidar com as questões ambientais e têm dificuldade em trabalhar a educação ambiental em seus espaços profissionais?

Teorizando sobre os pressupostos apontados, elencamos objetivos/propostas que seriam, ao longo do percurso, investigados para uma proposição metodológica ou pontos que culminariam com a educação ambiental nos espaços de formação de professores: intervir junto aos professores universitários dos cursos de licenciaturas para propiciar contribuições teóricas e práticas relacionadas às questões ambientais; investigar como a educação ambiental vem sendo contemplada nos cursos de formação de professores, contribuindo para um redimensionamento do currículo, de forma que propicie a preservação do meio ambiente e a conscientização ambiental; averiguar documentos legais para detectar as concepções de EA, bem como propor metodologias e atividades que contemplem a EA nos currículos dos cursos de formação de professores.

Nesse contexto, nas pesquisas relacionadas à EA, torna-se imprescindível uma abordagem histórica da educação ambiental e de como são colocados em prática os conhecimentos ambientais, contribuindo com o que preconizam os PCNs, especificamente sobre o tema transversal Meio Ambiente. 
É necessário que, mais do que informações e conceitos, a escola e os professores se proponham a trabalhar com atitudes, com formação de valores, com o ensino e a aprendizagem de procedimentos. Gestos de solidariedade, hábitos de higiene pessoal e dos diversos ambientes e participação em pequenas negociações são exemplos de aprendizagem que podem ocorrer na escola.

Assim, a grande tarefa da escola é proporcionar um ambiente escolar saudável e coerente com aquilo que ela pretende que seus alunos apreendam, a fim de que possa, de fato, contribuir para a formação da identidade de cidadãos conscientes de suas responsabilidades com o meio ambiente, capazes de atitudes de proteção e melhoria em relação ao ambiente. Cabe à escola, também, garantir situações em que os alunos possam pôr em prática sua capacidade de atuação, a exemplo de pesquisas e estudos no campo, como excursões e estudo do meio.

Entretanto, não se pode esquecer que a escola não é o único agente educativo e que os padrões de comportamento da família e as informações veiculadas pela mídia exercem especial influência sobre adolescentes e jovens. Os meios de comunicação e a imprensa constituem uma fonte de informações sobre o meio ambiente para a maioria das pessoas, sendo, portanto, inegável sua importância no desencadeamento dos debates que podem gerar transformações e soluções efetivas dos problemas locais. Por isso, é importante que os professores não apenas informem, mas também trabalhem as informações de forma crítica e construtiva.

Com essa compreensão, a efetivação de uma proposta para a educação ambiental na formação de professores se faz necessária e perpassa, principalmente, pelo redimensionamento do currículo dos cursos superiores, em especial das licenciaturas. Dentre os procedimentos metodológico-interventivos dentro de uma metodologia participativa, sugerem-se: cursos de educação continuada para os professores, tanto presencial como a distância; oficinas com relatos de experiências e confecção de materiais recicláveis; encontros periódicos para discussões sobre questões ambientais, intensificadas em datas comemorativas com exposições e utilização de recursos audiovisuais (vídeos, filmes, documentários, reportagens, envolvendo todos os profissionais da instituição e a comunidade); excursões no próprio município e no estado; conhecer e intervir na realidade vivenciada pela população do município, em campanhas informativas/conscientizadoras no entorno geográfico da instituição formadora e levadas para escolas públicas e outras, de acordo com a disponibilidade dos sujeitos envolvidos (professores, gestores, autoridades na área). 


\section{Teorizando sobre educação ambiental e sua inserção nos cursos de formação de professores}

De acordo com Dias (2000), a evolução dos conceitos de educação ambiental esteve diretamente relacionada à evolução do conceito de meio ambiente e ao modo como este era percebido. Dessa forma, podem-se analisar vários conceitos de EA no decorrer de sua história.

Em 1969, a educação ambiental foi definida como um processo que deveria objetivar a formação de cidadãos. Um ano após a formulação desse conceito, a Internacional Union for the Nature (IUCN) definiu a EA como um processo de reconhecimento de habilidades e atitudes necessárias à compreensão e à apreciação das inter-relações entre o homem, sua cultura e seu entorno biofísico.

Na década de 1970, Meadows (1999) apresentou a educação ambiental como um processo no qual deveria ocorrer um desenvolvimento progressivo do senso de preocupação com o meio ambiente, baseado em um complexo e sensível entendimento das relações do homem com o ambiente a sua volta. Em 1977, na conferência realizada em Tbilisi (antiga URSS), postulou-se que a EA é um elemento essencial para uma educação global, orientada para resolução dos problemas concretos, em favor do bem-estar da comunidade humana e do meio ambiente, por meio de um enfoque interdisciplinar e de uma participação ativa e responsável de cada indivíduo e da coletividade.

Na Conferência Rio-92, a comissão internacional responsável pela preparação do encontro mundial expôs que a EA, por incorporar as dimensões socioeconômica, política, cultural e histórica, não pode basear-se em pautas rígidas e de aplicação universal, devendo considerar as condições e o estágio de cada país, região e comunidade, sob uma perspectiva holística. Assim sendo, a EA deve permitir a compreensão da natureza complexa do meio ambiente e interpretar a interdependência entre os diversos elementos que constituem o ambiente, com vistas a utilizar racionalmente os recursos do meio, na satisfação material e espiritual da sociedade, no presente e no futuro.

O Conselho Nacional do Meio Ambiente (Conama), na publicação intitulada Subsídios para a formulação de uma política nacional de educação ambiental (BRASIL, 1996), definiu a EA como um processo de formação e informação, orientado para o desenvolvimento da consciência crítica sobre as questões ambientais e de atividade que levem à participação das comunidades na preservação do equilíbrio ambiental.

Em 27 de abril de 1999, foi criada a Lei n 9.795, que “dispõe sobre a Educação Ambiental, institui a Política Nacional de Educação Ambiental e dá outras providências". A definição da EA encontra-se no artigo 13: "Entende-se por educação 
ambiental não-formal as ações e práticas educativas voltadas à sensibilização da coletividade sobre as questões ambientais e à sua organização e participação na defesa da qualidade do meio ambiente" (BRASIL, 1999). Em seu artigo $2^{\circ}$, cita que a educação ambiental deve ser um componente essencial e permanente da educação nacional, devendo estar presente, de forma articulada, em todos os níveis e modalidades do processo educativo, em caráter formal e não formal, ou seja, precisa ocorrer para além dos muros da escola.

No início do século XXI, Medina (2000) relatou que a educação ambiental é um processo que consiste em propiciar às pessoas uma compreensão crítica e global do ambiente, para elucidar valores e desenvolver atitudes que lhes permitam adotar uma posição consciente e participativa a respeito das questões relacionadas com a conservação e a adequada utilização dos recursos naturais, para a melhoria da qualidade de vida e a eliminação da pobreza extrema e do consumismo desenfreado.

A Secretaria de Meio Ambiente do estado de São Paulo criou, em 1999, os Cadernos de Educação Ambiental. Nessa série, o trabalho desenvolvido por Donella H. Meadows (1999), que traz várias definições de EA, foi traduzido e divulgado em todo o país. Para essa autora, em linhas gerais, a EA é a preparação de pessoas para a vida enquanto membros da biosfera; é o aprendizado para compreender, apreciar, saber lidar e manter os sistemas ambientais na sua totalidade. Além disso, a EA significa aprender a ver o quadro global que cerca um problema específico - a história, os valores, as percepções, os fatores econômicos e tecnológicos e os processos naturais ou artificiais que causam tal problema e que sugerem ações para saná-lo (BRASIL, 2007).

Educação ambiental é a aprendizagem de como gerenciar e melhorar as relações entre a sociedade humana e o ambiente, de modo integrado e sustentável. Ela mostra como aprender a empregar novas tecnologias, aumentar a produtividade, evitar desastres ambientais, minorar os danos existentes, conhecer e utilizar novas oportunidades e tomar decisões acertadas.

Marco importante nessa questão foi a Conferência Intergovernamental sobre Educação Ambiental, em Tbilisi, na qual foram colocadas algumas recomendações aos países participantes para por em prática o que havia sido discutido durante a reunião. Conhecida como "Conferência de Tbilisi", sua declaração foi publicada na íntegra (UNESCO/PNUMA, 1980), com objetivos, funções, estratégias e características da educação ambiental. Como finalidades da EA, constam nesse documento: ajudar a fazer e compreender claramente a existência da interdependência econômica, social, política e ecológica, nas zonas urbanas e rurais; proporcionar a todas as pessoas a possibilidade de adquirir os conhecimentos, o sentido dos valores, o interesse ativo e as atitudes necessários para proteger e melhorar o meio ambiente; 
induzir novas formas de conduta nos indivíduos, nos grupos sociais e na sociedade em seu conjunto a respeito do meio ambiente (UNESCO/PNUMA, 1980).

Nessa ótica, registra-se que, para os países periféricos, como é o caso do Brasil, a degradação ambiental está indissoluvelmente vinculada à pobreza e à escassez de oportunidades, dentre as quais poderemos aglutinar a carência educacional dos povos (COMISSÃO DE DESENVOLVIMENTO E MEIO AMBIENTE DA AMÉRICA LATINA E DO CARIBE, 1992).

Apenas recentemente é que os países ricos ou desenvolvidos, como os EUA e os membros da União Europeia, estão se preocupando com as questões ambientais, pois assumiram, pelo menos na teoria, a condição de disponibilidade de recursos financeiros para diminuir a degradação do planeta.

A Constituição da República Federativa do Brasil, promulgada em 1988, dedica o capítulo VI às questões ambientais, o qual determina que: "Todos têm direito ao meio ambiente ecologicamente equilibrado, bem de uso comum do povo e essencial à sadia qualidade de vida, impondo-se ao poder público e à coletividade o dever de defendê-lo e preservá-lo para as presentes e futuras gerações" (BRASIL, 1988). Especificamente, no artigo 225, a Carta Magna estabelece: "Promover a educação ambiental em todos os níveis de ensino e a conscientização pública para a preservação do meio ambiente" (BRASIL, 1988).

Dessa forma, é necessário que os cursos de formação de professores abordem temáticas voltadas para as questões que assolam o meio socioambiental, no sentido de conscientizar a população para preservar e conservar os recursos naturais, obtendo resultados eficazes no que diz respeito à qualidade de vida e ao ambiente equilibrado para as futuras gerações, inclusive com maior sensibilização e ações voltadas para evitar os problemas atuais.

Percebemos, em nossa trajetória, que um dos entraves no trato com as questões ambientais, especificamente com a educação ambiental, por parte dos professores, é a ausência de conhecimentos pertinentes à temática, tanto na sua formação inicial quanto na continuada. Por isso a proposta de se trabalhar com os professores dos cursos de licenciatura para tentar sugerir conhecimentos teóricos e práticos em sua formação, contribuindo para a conscientização e a sensibilização no tocante ao meio ambiente, para que eles, em sua atuação, exerçam a "cidadania ambiental".

Nesse sentido, a compreensão das questões ambientais pressupõe um trabalho interdisciplinar. A análise de tais questões envolve outras de caráter político, histórico, econômico, ecológico, geográfico; enfim, envolve processos variados; portanto, não seria possível compreendê-los e explicá-los pelo olhar de uma única ciência; por essa razão a necessidade de os cursos de formação de professores terem o foco interdisciplinar. 
Segundo Ivani Fazenda, "[...] a interdisciplinaridade não se ensina nem se aprende, apenas vive-se, exerce-se [...] é uma questão de atitude" (1999, p. 65). Como sinônimo de complexidade, está longe de ser apenas fusão de conteúdos ou métodos, ao invés de se prender nos elementos, busca sempre as relações entre eles, ou seja, trabalha-se sempre com uma estrutura de relações.

A interdisciplinaridade significa uma prática que rompe com barreiras disciplinares, em que cada disciplina possa apontar suas contribuições sobre um determinado assunto que seja trabalhado em todas as disciplinas, a ponto de possibilitar uma visão globalizante sobre o assunto, possibilitando uma aprendizagem significativa e abrangente.

A interdisciplinaridade jamais ignora as 'condições efetivas, sociais e históricas, sob as quais existem e funcionam a ciência e o homem de ciência contemporânea' (Castoriadis). Sendo assim, afirmo que um trabalho interdisciplinar crítico (não ingênuo), diz respeito às inúmeras interações e interferências, e, portanto, é sinônimo de complexidade. Como sinônimo de complexidade, a interdisciplinaridade não se ensina [...] (SIQUEIRA, 2003, não paginado).

Para que essa concepção se concretize na escola, é necessário o redimensionamento de ações e do próprio currículo, pois, de certa forma, o currículo educacional ainda é concebido como um receituário formal dos conhecimentos a serem ministrados num determinado período. Nas palavras de Ramalho et al., "[...] o currículo pode ser compreendido como o percurso que leva à aquisição de conhecimentos que possam fazer do indivíduo, a ele submetido, um profissional que domina sua área" (2003, p. 42). Contudo, se há algumas décadas os ensinos de Português, Matemática, Ciências, História, Geografia, etc., enfim, disciplinas historicamente indispensáveis, bastavam para a formação do indivíduo, hoje, além de se permitirem abordagens multi e transdisciplinares, o currículo busca privilegiar conteúdos que, para além da exigência contemporânea, inscrevam-se como articulares do próprio futuro social e político. É o caso, por exemplo, das práticas relacionadas à tecnologia ou à pesquisa biológica e até mesmo as relacionadas ao meio ambiente.

O processo de determinação curricular consiste na definição dos aspectos centrais e estruturantes de um currículo, gerado e desenvolvido no âmbito social amplo, articulado a projetos sociopolíticos (RAMALHO et al., 2003). Consequentemente, o encontro entre o pensar educativo e o fazer social dá-se naquilo que se poderia chamar contexto cultural. Antes da formalização do currículo, há a necessidade de instaurar-se determinada cultura, sob pena de criar-se um ambiente artificialmente formal. Nesse sentido, os autores mencionados direcionam para uma cultura educacional na atualidade pautada pela globalização excludente, geradora, por conseguinte, do agravamento da desigualdade social. Logo, o que se concebe 
para a elaboração de uma dinâmica profissional estabelece as premissas de novas concepções disciplinares.

Por um "processo de integração contínua, de caráter transversal”, entenda-se uma sistemática capaz de atender às expectativas da própria formação do indivíduo em sua trajetória como educando, aprendiz e cidadão. A própria descrição acedida pelo Parecer CNE/CP9/2001, sobre as Diretrizes Curriculares Nacionais para a Formação de Professores da Educação Básica, inscreve com objetividade o conceito de continuidade e de transversalidade, ao alertar sobre a superficialidade com a qual se tratam os conteúdos, impedindo-os de que dialoguem com a produção contínua do conhecimento (ARAÚJO et al., 2008).

Com esse contexto, como diz Sachs, espera-se:

Um novo tipo de desenvolvimento que deve procurar a harmonia da sociedade com a natureza. Em sua ausência, a imbricação dos fenômenos de degradação ambiental e de decadência social levará fatalmente ao mau desenvolvimento. Numa ótica pró-ativa, um desenvolvimento não é apenas um critério de avaliação da trajetória da história, mas também um conceito normativo orientado para o futuro, procurando conhecer as estratégias de transição escalonadas em várias décadas, que permitissem passar do círculo vicioso do mau desenvolvimento social e da degradação ambiental para o círculo virtuoso do desenvolvimento que responde à racionalidade socioecológica (1992, p. 124).

Corroborando essa concepção, tem-se que o longo período de instabilidade econômica do Brasil - um dos países mais perversos do continente em termos de distribuição de renda -, de certa forma, elevou o número de pessoas que vivem abaixo da linha de pobreza absoluta. Segundo dados do INSTITUTO BRASILEIRO DE GEOGRAFIA E ESTATÍSTICA(IBGE) (2011), no Brasil, 8,5\% da população viviam em famílias com renda inferior à fixada pela linha de indigência, e 15,1\% abaixo da linha de pobreza. A maior parte desse contingente está concentrada na Região Nordeste e nas áreas metropolitanas.

Além de existirem nas cidades enormes contingentes de cidadãos com escassa vivência de direitos políticos básicos, as instituições canalizadoras de participação rearticulam-se com lentidão para conduzir as novas possibilidades de um jogo político pluralista. De certa forma, tal situação favoreceu formas clientelistas de condução do sistema político e da administração pública, o que limitou ainda mais a consolidação de instituições e padrões de conduta efetivamente democrática (ANDRADE, 1998).

Além disso, acumula-se a dívida social, que no Nordeste brasileiro assume maior dimensão. Na região, onde se concentram $30 \%$ da população do Brasil, encontram-se também mais de 52\% dos analfabetos brasileiros (IBGE, 2011), o que reforça a necessidade de educação e de escolarização para atender a esse con- 
tingente estudantil, visto que, com índices elevados de educação, há significativo avanço no ambiente social e natural do homem.

A situação política mudou e, com ela, continuam mudando os valores, as prioridades, os objetivos educacionais. A crise na educação está diretamente associada às transformações ocorridas no projeto coletivo estruturado em novas bases valorativas. Entre nós, a crise na educação e, também, a ambiental costumam ser associadas à falta de recursos, ao mau funcionamento das instituições, ao despreparo e à baixa remuneração dos profissionais envolvidos com a educação e com o meio ambiente, especificamente os professores. Embora essas associações não sejam desprovidas de significado, elas traduzem apenas uma parte dos problemas. Situá-las no centro das atenções pode constituir uma simplificação e conduzir às análises que representam apenas meias-verdades (MACHADO, 2000).

Mencionando novamente os PCNs, por sua natureza aberta, configuram uma proposta flexível, a ser concretizada nas decisões regionais e locais sobre currículos e sobre programas de transformação da realidade educacional empreendidos pelas autoridades governamentais, pelas escolas e pelos professores. Eles não configuram um modelo curricular homogêneo e impositivo, que se sobreporia à competência político-executiva dos estados e municípios, à diversidade sociocultural das diferentes regiões do país ou à autonomia de professores e equipes pedagógicas. Os parâmetros e/ou diretrizes, como já aludido, tratam da educação ambiental no tema transversal Meio Ambiente, que traz como objetivo geral,

[...] considerando-se a importância da temática ambiental e a visão integrada de mundo, tanto no tempo como no espaço, a escola deverá, ao longo das nove séries do ensino fundamental, oferecer meios efetivos para que cada aluno compreenda os fatos naturais e humanos a esse respeito, desenvolva suas potencialidades e adote posturas pessoais e comportamentos sociais que lhe permitam viver numa relação construtiva consigo mesmo e com seu meio, colaborando para que a sociedade seja ambientalmente sustentável e socialmente justa; protegendo, preservando, todas as manifestações de vida no planeta; e garantindo as condições para que ela prospere em toda a sua força, abundância e diversidade (BRASIL, 1998a, p. 197, grifo nosso).

Nos PCNs, os conteúdos de Meio Ambiente foram integrados às áreas, numa relação de transversalidade, de modo que impregne toda a prática educativa e, ao mesmo tempo, crie uma visão global e abrangente da questão ambiental, visualizando os aspectos físicos e histórico-sociais, assim como as articulações entre a escala local e global desses problemas.

Cada professor, dentro da especificidade de sua área, deve adequar o tratamento dos conteúdos para contemplar o tema Meio Ambiente. Essa adequação pressupõe um compromisso com as relações interpessoais no âmbito da escola para que haja explicitação dos valores que se pretendem transmitir e coerência entre 
esses e os experimentados na vivência escolar, buscando desenvolver a capacidade de todos para intervir na realidade e transformá-la.

Para isso, é imprescindível que a educação ambiental seja inserida nas várias áreas do saber. Na elaboração dos PCNs, por exemplo, essas áreas apontaram a relação de seus conteúdos com o tema Meio Ambiente, e algumas destacaram um bloco de conteúdos ou um eixo temático que trata diretamente da relação sociedade/natureza ou vida/ambiente. Isso retrata a dimensão do trabalho que se deseja com essa questão, diante das necessidades impostas pela realidade socioambiental.

\section{Considerações finais}

Diante do exposto, e concordando com Medina e Santos (1999), os educandos só conseguirão mudar sua maneira de pensar o ambiental se a educação não permanecer alheia às novas condições de seu entorno, as quais exigem respostas inovadoras e criativas, que permitam formar efetivamente o cidadão crítico, reflexivo e participativo, apto para a tomada de decisões que sejam condizentes com a consolidação de democracias verdadeiras e sem exclusão da maioria dos membros. Nessa ótica, a educação ambiental seria grande enriquecedora e modificadora do contexto educacional, pois estaria trabalhando com a aprendizagem de atitudes e valores. A eficácia desse processo ensino/aprendizagem está em substituir a aprendizagem memorística pela aprendizagem significativa.

A educação ambiental perpassa, como discorrido ao longo do texto, por uma questão de interdisciplinaridade, que transfere métodos de algumas disciplinas para outras, identificando novos objetos de estudo. É uma postura frente à totalidade do conhecimento, que substitui a concepção fragmentária pela unitária do ser humano.

A questão ambiental se tornou um tema de interesse planetário e, ao mesmo tempo, com ênfase local, que precisa cada vez mais ser discutido em toda a extensão da sociedade, da escola e da família. Diante dessa realidade, torna-se fundamental o papel do professor como formador de opinião.

Conforme assegura Lemos et al.: "Os formadores de opinião têm a função de coletar, transmitir informações e esclarecer a população sobre assuntos relevantes para a sociedade como um todo, sendo a questão ambiental um dos temas que devem fazer parte de suas atenções" (1997, p. 2). Isso requer especial atenção ao processo de formação de educadores ambientais, tanto no que se refere à formação inicial quanto à formação continuada. Para isso, é fundamental ampliar as relações de fomento e parceria com as instituições de ensino superior, principalmente as universidades públicas, a exemplo do que já está acontecendo com a UAB, para 
a promoção de cursos de curta, média e longa duração, além de incluir em seus projetos pedagógicos atividades e conhecimentos pertinentes à temática ambiental. É indispensável, também, estimular os debates e propor a reorganização das licenciaturas, incluindo a pedagogia, como forma de assegurar a presença ou mesmo a obrigatoriedade da educação ambiental nos cursos de formação inicial dos professores, assim como traçar políticas que contemplem a participação de professores em cursos voltados para a temática, com elaboração e implementação de projetos e programas em educação ambiental (BRASIL, 2005).

Portanto, reforça-se a importância da educação ambiental bem como de sua inclusão no currículo dos cursos de formação de professores, de forma obrigatória, pois ela contribuirá para um aperfeiçoamento na melhoria da qualidade de vida das pessoas e, consequentemente, na formação da cidadania por meio de atitudes pertinentes à prática pedagógica.

Por fim, a questão ambiental na formação de professores para atuar na educação básica requer constructos de conhecimentos específicos da área ambiental, metodológicos e, sobretudo, pedagógicos, que contribuam com a formação inicial para lidar com as questões socioambientais. Esses conhecimentos serão fornecidos ao longo da educação do indivíduo, aperfeiçoando-se nas instituições formadoras de professores.

\section{Referências}

ALPHANDERY, Pierre. O equívoco ecológico: riscos da inconseqüência. São Paulo: Brasiliense, 1992.

ANDRADE, Lenaldo Alves de. Manejo e conservação de recursos naturais renováveis. Brasília: ABEAS, 1998. (Curso de Desenvolvimento Sustentável para o Semi-Árido Nordestino, módulo 2).

ARAÚJO, Maria Inês et al. (Org.). Desafios da formação de professores para o século XXI: o que deve ser ensinado? O que deve ser aprendido? São Cristóvão: Editora UFS, 2008.

BRANCO, Samuel Murgel. O meio ambiente em debate. São Paulo: Moderna, 1998.

BRASIL. Constituição da República Federativa do Brasil. Brasília, DF: Senado, 1988.

. Parâmetros curriculares nacionais: temas transversais meio ambiente e saúde. Brasília: MEC/SEF, 1998a.

Parâmetros curriculares nacionais: terceiro e quarto ciclos - apresentação dos temas transversais. Brasília: MEC/SEF, 1998b.

. Subsídios para a formulação de uma política nacional de educação ambiental. Brasília: Conama/MMA/MEC, 1996. 
. Lei no 9.795, de 27 de abril de 1999. Dispõe sobre a Educação Ambiental, institui a Política Nacional de Educação Ambiental e dá outras providências. Diário Oficial da União, Brasília, DF, 28 abr. 1999.

. Ministério da Educação. Secretaria de Educação Continuada, Alfabetização, Diversidade e Inclusão - Secadi. Programas e Ações. Brasília: MEC/Secadi, 2012. Disponível em: <http:// portal.mec.gov.br/secretaria-de-educacao-continuada-alfabetizacao-diversidade-e-inclusao/programas-e-acoes>. Acesso em: 23 dez. 2014.

MMA/MEC. Programa Nacional de Educação Ambiental - ProNEA. 3. ed. Brasília: MMA/MEC, 2005.

. Ministério da Educação. Coordenação Geral de Educação Ambiental: Ministério do Meio Ambiente. Vamos cuidar do Brasil: conceitos em educação ambiental na escola. Brasília: MMA/ MEC/UNESCO, 2007.

CHARLOT, Bernard. Relação com o saber, formação dos professores e globalização: questões para a educação hoje. Porto Alegre: Artmed, 2005.

DIAS, Genebaldo Freire. Educação ambiental: princípios e práticas. 6. ed. São Paulo: Gaia, 2000.

FAZENDA, Ivani Catarina Arantes. Práticas interdisciplinares na escola. São Paulo: Cortez, 1999.

COMISSÃO DE DESENVOLVIMENTO E MEIO AMBIENTE DA AMÉRICA LATINA E DO CARIBE. Nossa própria agenda. São Paulo: BID/PNUD, 1992.

INSTITUTO BRASILEIRO DE GEOGRAFIA E ESTATÍSTICA. Pesquisa nacional por amostra de domicílio 2011. Rio de Janeiro: IBGE, 2011. Disponível em: <http://www.ibge.gov.br/home/ presidencia/noticias/imprensa/ppts/00000010135709212012572220530659.pdf>. Acesso em: 9 jan. 2014.

LEÃO, Ana Lucia Carneiro. Educação ambiental: um desafio conquistado dia a dia. Revista Educação Ambiental em Ação, ano 1, n. 1, jun./ago. 2002. Disponível em: <http://www.revistaea.org/ artigo>. Acesso em: 24 out. 2007.

LEMOS, Ângela Denise da Cunha et al. O perfil dos formadores de opinião relacionados às questões ambientais: o caso de duas empresas brasileiras de mídia impressa. In: SEMINÁRIO LATINO-AMERICANO DE GESTIÓN TECNOLÓGICA, 7, 27-29 de outubro de 1997, Havana, Cuba. Anais... Havana: [s.n.], 1997.

MACHADO, Nilson José. Epistemologia e didática: as concepções de conhecimento e inteligência e a prática docente. São Paulo: Cortez, 2000.

MEADOWS, Donela. Conceitos para se fazer educação ambiental. São Paulo: Secretaria do Meio Ambiente de São Paulo, 1999.

MEDINA, Naná Mininni. A formação dos professores em educação ambiental. In: TEXTOS sobre capacitação em Educação Ambiental. Oficina Panorama da Educação Ambiental. Brasília: MEC-SEF-DPEF; Coordenação de Educação Ambiental, 2000. p. 17-24.

MEDINA, Naná Mininni; SANTOS, Conceição Elizabeth. Educação ambiental: uma metodologia participativa de formação. Petrópolis, RJ: Vozes, 1999. 
RAMALHO, Betânia leite et al. Formar o professor, profissionalizar o ensino: perspectivas e desafios. Porto Alegre: Sulina, 2003.

SACHS, Ignacy. Qual desenvolvimento para o século XXI? In: BARRERE, Martine (Coord.). Terra, patrimônio comum: a ciência a serviço do meio ambiente e do desenvolvimento. São Paulo: Nobel, 1992. p. $117-130$.

SIQUEIRA, Holgonsi Soares Gonçalves. Interdisciplinaridade, sinônimo de complexidade. Publicado no Jornal A Razão, Santa Maria, 02 out. 2003. Disponível em: <http://www.angelfire. com/sk/holgonsi/interdiscip4.html>. Acesso em: 10 out. 2007.

TOZONI-REIS, Marilia Freitas de Campos. Educação ambiental: natureza, razão e história. Campinas, SP: Autores Associados, 2004.

UNESCO/PNUMA. La educación ambiental: las grandes orientaciones de la conferencia de Tbilisi. Paris: UNESCO, 1980. 